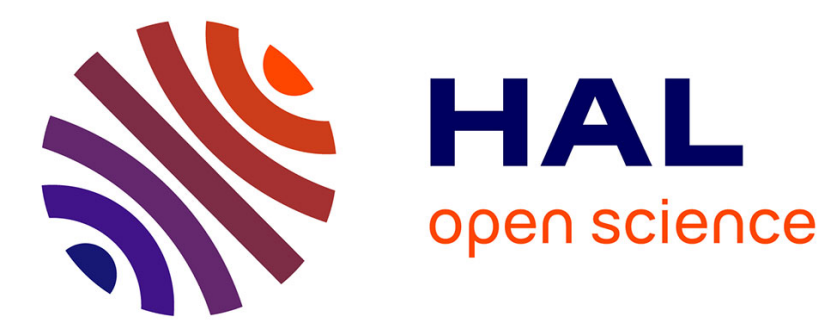

\title{
Assessment of adult speech disorders: current situation and needs in French-speaking clinical practice
}

\author{
Timothy Pommée, Mathieu Balaguer, Julie Mauclair, Julien Pinquier, \\ Virginie Woisard
}

\section{- To cite this version:}

Timothy Pommée, Mathieu Balaguer, Julie Mauclair, Julien Pinquier, Virginie Woisard. Assessment of adult speech disorders: current situation and needs in French-speaking clinical practice. Logopedics Phoniatrics Vocology, 2021, pp.1-15. 10.1080/14015439.2020.1870245 . hal-03120115

\section{HAL Id: hal-03120115 https://hal.science/hal-03120115}

Submitted on 25 Jan 2021

HAL is a multi-disciplinary open access archive for the deposit and dissemination of scientific research documents, whether they are published or not. The documents may come from teaching and research institutions in France or abroad, or from public or private research centers.
L'archive ouverte pluridisciplinaire HAL, est destinée au dépôt et à la diffusion de documents scientifiques de niveau recherche, publiés ou non, émanant des établissements d'enseignement et de recherche français ou étrangers, des laboratoires publics ou privés. 


\section{Logopedics Phoniatrics Vocology}

\section{Assessment of adult speech disorders: current situation and needs in French-speaking clinical practice}

Timothy Pommée, Mathieu Balaguer , Julie Mauclair , Julien Pinquier \& Virginie Woisard

To cite this article: Timothy Pommée , Mathieu Balaguer , Julie Mauclair , Julien Pinquier \& Virginie Woisard (2021): Assessment of adult speech disorders: current situation and needs in French-speaking clinical practice, Logopedics Phoniatrics Vocology

To link to this article: https://doi.org/10.1080/14015439.2020.1870245

$$
\text { 曲 Published online: } 11 \text { Jan } 2021 .
$$

Submit your article to this journal $\pi$

Q View related articles

View Crossmark data $\nearrow$ 


\title{
Assessment of adult speech disorders: current situation and needs in French-speaking clinical practice
}

\author{
Timothy Pommée $^{\mathrm{a}}$ (D), Mathieu Balaguer ${ }^{\mathrm{a}, \mathrm{b}}$, Julie Mauclair ${ }^{\mathrm{a}}$, Julien Pinquier ${ }^{\mathrm{a}}$ and Virginie Woisard ${ }^{\mathrm{b}, \mathrm{c}, \mathrm{d}}$ \\ ${ }^{\mathrm{a} I R I T}$, CNRS, University Paul Sabatier, Toulouse, France; ${ }^{\mathrm{b}}$ ENT department, University Hospital of Toulouse Larrey, Toulouse, France; \\ 'Oncorehabilitation unit, University Cancer Institute of Toulouse Oncopole, Toulouse, France; ${ }^{\mathrm{d}}$ Laboratoire Octogone Lordat, Jean Jaurès \\ University Toulouse II, Toulouse, France
}

\begin{abstract}
Introduction: Speech assessment methods used in clinical practice are varied and mainly perceptual and motor. Reliable assessment of speech disorders is essential for the tailoring of the patient's treatment plan.

Objective: To describe current clinical practices and identify the shortcomings and needs reported by French-speaking clinicians regarding the assessment of speech disorders in adult patients.

Methods: Data were collected using an online questionnaire for French-speaking speech and language pathologists (SLPs) in Belgium, France, Switzerland, Luxembourg, and Maghreb. Forty-nine questions were grouped into six domains: participant data, educational and occupational background, experience with speech disorders, patient population, tools and tasks for speech assessment, and possible lacks regarding the current assessment of speech disorders.

Results: Responses from 119 clinicians were included in the analyses. SLPs generally use "à la carte" assessment with a large variety of tasks and speech samples. About one quarter of them do not use existing assessment batteries. Those who do mostly use them partially. Pseudo-words are rarely used and are absent from standardized batteries, in contrast to the major use of words and sentences. Perceptual evaluation largely prevails (mainly overall ratings of speech "intelligibility", "severity," and "comprehensibility" and percent-correct phonemes), whereas the recording equipment for acoustic measures is not standardized and only scarcely described by the SLPs. The most commonly used questionnaire to assess the functional impact of the speech disorder is the Voice Handicap Index; one quarter of the SLPs does not use any questionnaire. Overall, the available tools are considered only moderately satisfactory. The main reported shortcomings are a lack of objectivity and reproducibility of speech measures; exhaustiveness and consideration of specific speech parameters (prosody, speech rate, and nasality); practicality of the assessment tools.

Conclusion: This study highlights a lack of standardization of the speech assessment in French-speaking adults and the need to offer new reliable tools for an optimized, accurate speech assessment. The automation of these tools would allow for rapid, reproducible, and accurate measures.
\end{abstract}

\section{ARTICLE HISTORY}

Received 9 June 2020

Revised 13 December 2020

Accepted 26 December 2020

\section{KEYWORDS}

Speech; assessment; French; survey

\section{Introduction}

Speech disorders (SD) in adults can be caused by various pathologies. These difficulties may be functional, of neurological origin such as in motor speech disorders (dysarthria and apraxia) or result from structural deficits ${ }^{1}$ such as malformations of the oral/pharyngeal apparatus, after-effects of radiotherapeutic and/or surgical treatment of ENT cancer, and velar insufficiency [1]. They can be either congenital or acquired $[1,2]$.

SDs can have a significant impact on the patients' daily life and on their communication, affect psychosocial dynamics, and reduce their quality of life [3-12]. This underlines the importance of an accurate assessment of the underlying deficits for targeted care.

The speech assessment is aimed at evaluating several dimensions of the speech disorder, which can be grouped according to the ICF classification [13] - into three levels.
The first level of analysis is the body structure and functions, where the clinician needs to integrate information about the pathological context, about structural deficits/ modifications, and their stable or evolving nature. This level includes the examination of each of the three main speech subsystems: respiration, phonation, and articulation. The clinician assesses the patient's posture, breathing at rest and during speech, pneumo-phonic coordination, phonatory function, resonance, motricity and sensitivity of the articulators, and coordination, programming, and planning of articulatory movements $[14,15]$. The second level, activities, concerns the limitations that the impairment induces on the patient's communication, on his/her ability to share information with a listener. At this level, two dimensions have to be distinguished: intelligibility and the functional communication ability. Intelligibility can be defined as the accuracy with which the acoustic signal produced by the speaker is 
decoded by the listener [2,16-18]. It is an analytical acoustic-phonetic decoding concept, which refers to the pronunciation quality of "low-level" units (phonemes/phonemic groups/syllables). It should be distinguished from comprehensibility, which can be defined as "the ability of the listener to interpret the meaning of the oral message produced by a speaker without regard to phonetic or lexical accuracy or correctness" [2]. Comprehensibility is therefore a signalindependent, more functional concept, complementary to intelligibility in the "activities" level of the speech assessment. It takes into account many factors in the communication context (semantic, syntactic and discursive context, situational clues, gestures... ) [16-19], which can help the listener to compensate a possible degradation of the speech signal [20]. Note that while the underliers of speech intelligibility (respiration, phonation, articulation) can be analyzed at the "body structures and functions" level, the construct of intelligibility per se is considered as pertaining to the use of the body structure and functions to produce intelligible speech, and is thereby included in the "activities" level of the ICF framework $[15,18]$. To assess intelligibility, both perceptual and acoustic measures can be used. Perceptual methods include the transcription and percent-correct stimuli score from repetition or reading aloud of isolated phonemes, syllables, pseudo-words or words in unpredictable sentences, or the use of minimal word pairs (i.e. any speech material that does not involve top-down processes that could compensate for a degraded speech signal). Acoustic methods include low-level segmental acoustic measures $[21,22]$, which allow for a stable and reliable outcome measure [23] - provided the clinician uses the exact same recording parameters and conditions as for the initial assessment. These analytical measures can for example allow the clinician to target specific speech sounds, sound categories, or speech parameters (e.g. increase lip tension in plosives) during therapy. Therapy goals aiming to reduce the speech deficits, along with compensatory approaches, will subsequently contribute to improving the patient's comprehensibility and functional communication [18,24-26].

At the third level of the ICF framework, the clinician needs to assess the participation level, namely the ability of the patient to interact with his/her environment and the restrictions the speech disorder will induce in his/her psychosocial context.

For each of these different levels, speech assessment methods used today are varied [27], mainly perceptual [28] and subjective: Clinicians can use visual analog scales, Likert scales, or direct magnitude estimation [29-32] to assess different concepts, both global (e.g. disorder severity, naturalness, speech clarity) or more specific (e.g. prosody, voice quality, speech rate). This can be done at different levels of granularity: on isolated phonemes, syllables, (pseudo-)words, sentences, reading passages, or conversations. Furthermore, the speech assessment usually includes orthographic stimuli transcriptions (usually of words or sentences) [17,20,33], but also assessment of the word/sentence comprehensibility by the use of closed sets of items [29,33] and assessment of narrative comprehensibility using questions [17]. Last but not the least, self-rated questionnaires are sometimes used to assess the patient's perception of the speech disorder, as well as the functional impact and the speech-related quality of life. In French, the most commonly used standardized speech assessment battery is the Batterie d'Evaluation Clinique de la Dysarthrie (BECD) [34], or its older version, the Evaluation Clinique de la Dysarthrie (ECD) [35]. This battery includes the Test Phonétique d'Intelligibilité, a French version of Kent's Single Word Intelligibility test $[29,36,37]$. Other available tests are the French version of Voier's diagnostic rhyme test [38] (mainly used in research because of its length [20]), the Test quantitatif d'intelligibilite [39], the French version of the Frenchay Dysarthria Assessment-Second Edition (FDA-2) [40], and the MonPaGe protocol [41]. To assess the functional impact of the speech disorder, two specific tools exist in French: the French version of Rinkel et al.'s Speech Handicap Index $[8,42]$ and the Phonation Handicap Index (PHI) [11,12]. Furthermore, the Carcinologic Handicap Index (CHI) was specifically created for head and neck cancer patients [43,44]. An extensive description of these assessment tools is beyond the scope of this work.

In light of the diversity of speech assessment methods, but also of the international variability of the SLP training, assessment practices have to be explored across countries and linguistic communities. Gaining a better insight into this topic allows for the development of clinical guidelines and new clinical tools and to inform the education systems training future SLPs [27].

While surveys have been carried out in different countries and linguistic communities [27,45-48], the current literature does not provide data on speech assessment practices in French-speaking countries. Therefore, by means of a survey for French-speaking SLPs/phoniatricians, a first aim of this study was to provide an overview of current clinical practices regarding the assessment of speech disorders in adult patients. This overview will then allow to address the second objective of this study, and to identify the shortcomings and needs reported by these clinicians regarding speech assessment in adults.

\section{Materials and methods}

\section{Study design}

Both qualitative and quantitative data for this cross-sectional descriptive mixed-method study were collected using an online survey. It was registered with the data protection officer of the Center National de la Recherche Scientifique (CNRS) and was also approved by the computer science ethics advisory board (Comité consuLtatif d'Éthique concernant la Recherche en Informatique de Toulouse - CLERIT) under the accreditation number 2018-11-30-10.

\section{Participants}

\section{Recruitment}

The online questionnaire targeted French-speaking clinicians (SLPs and phoniatricians) treating SDs in adults, as 
previously defined, in Belgium, France, Luxembourg, Switzerland, and Maghreb.

Recruitment was carried out throughout the period during which the questionnaire was online via:

- National professional associations (Fédération Nationale des Orthophonistes, Union Professionnelle des Logopèdes Francophones, Association Romande des Logopédistes Diplômés... );

- Social networks, where private groups dedicated to the targeted professions were also solicited;

- Other means, such as word-of-mouth and mailing lists of other organizations (e.g. the list of participants in a conference related to the topic).

While the overall number of active SLPs was approximately known (e.g. 25,607 active SLPs in France on 1 January 2019 [49], 6392 in the French-speaking regions of Belgium on 31 December 2018 [50], 105 in Luxembourg on 31 December 2017 [51], 76 in latin Switzerland hospitals in 2014 [52]), the hypothetical number of clinicians meeting the inclusion criteria as well as the sample size of the SLPs eventually contacted by the professional associations was not known to the authors. No hypothesis could thus be made on the expected number of responses. For comparison purpose, the sample sizes for other surveys targeting speech and language pathologists in the field of dysarthria were as follows: 296 in the USA [48], 80 in the Republic of Ireland [46], 146 [47] and 119 [45] in the UK, and 56 in Australia [27]. The only survey addressing SLPs working in the field of dysarthria in France targeted the north-western part of the country as well as Paris, and only obtained 20 responses [53].

\section{Ethical considerations}

An information notice describing the purpose of the questionnaire, the participant's rights, and the data privacy policy was provided to all participants prior to the survey. In order to avoid duplicates and to be able to contact participants if and only if they explicitly agreed, the questionnaire was not anonymized.

\section{The questionnaire}

\section{Design and construction of the questionnaire}

The online survey was carried out using the LimeSurvey platform. The questionnaire was open access, with built-in duplicate checking and security procedures. Two "filter" questions were used to check for compliance with the inclusion criteria and to terminate the participation in the event of a negative response. The first referred to the profession (SLP or phoniatrician), and the second to the treatment of adult patients with speech disorders as defined in the introduction (Yes/No).

The questionnaire consisted of 49 questions: eighteen open-ended (digital inputs, short texts and long texts) and 31 closed-ended (single and multiple choice, binary responses, rankings, Likert scales), grouped into six main categories:

1. Participant information

2. Data on the participant's educational and professional background and current practice, in order to be able to analyze assessment practices according to different clinician profiles

3. Information regarding professional experience in the field of SDs, in order to estimate the respondent's level of expertise

4. Questions about the patient population, to describe the target group for speech assessments

5. Data on hard-/software equipment and the speech assessment carried out for SDs, to review current practices

6. Information about any potential shortcomings in speech assessment

A few questions were optional, to avoid dropping out of the questionnaire in case of answering difficulties. A "comment" box was provided to allow the participants to supplement their answers if needed.

The questionnaire was piloted in order to get an estimate of the response time and to detect possible execution problems. A panel of eight clinicians was selected on the basis of their experience with adult speech disorders. The completion time was estimated to be about $35 \mathrm{~min}$, and some glitches and logical structure problems were corrected.

The final questionnaire was launched on 25 January 2019 and was available until 31 May 2019. It is still available online for the reader ${ }^{2}$.

\section{Statistical data analysis}

The data were analyzed using Stata/MP software (version 14, StataCorp, College Station, TX).

The Shapiro-Wilk test, recommended for small samples, was first used to test for normality of the data distributions in quantitative variables and led to the choice of nonparametric analyses.

Descriptive statistics were performed on all quantitative and qualitative data and served as the basis to describe the clinical practices of French-speaking clinicians, as well as the reported needs and shortcomings.

The exact Fisher's test, suitable for small samples and categorical qualitative data, was used to investigate possible differences in self-assessed level of expertise in speech assessment and sufficiency of assessment tools among the clinicians:

- The relationship between the proportion of SDs in the patient group and the level of expertise in the assessment of SDs. The corresponding research question is "Do clinicians with a higher proportion of SD in their patient group report a higher level of expertise in the assessment of SDs?" 
- The relationship between the perceived sufficiency of assessment tools and the number of SD assessments performed per quarter. The corresponding research question is "Do clinicians who carry out a high number of SD assessments feel differently about the sufficiency of speech assessment tools?"

Logistic regressions were used in order to investigate whether the self-assessed level in the assessment of SDs is related to the number of years of SD treatment and to the number of speech-related continuous training courses, adjusting for the total number of SD-related training courses and for the number of years of SD treatment, respectively. The odd ratios (OR) allow for the study of the link between a quantitative variable of interest (here the self-assessed level) and one or more other explanatory variables.

The Mann-Whitney U-test was used to investigate the difference between satisfaction with quantitative and qualitative assessment tools.

Lastly, the Kruskal-Wallis test was used to analyze the influence of the number of years of experience in SD treatment as well as of the number of SD-related continuous training courses on the perceived sufficiency of the assessment tools.

To illustrate the shortcomings and possible solutions mentioned by the clinicians with regard to speech assessment tools, clinicians' open-ended answers were first analyzed by two independent raters blinded to the identity of the participants. This content analysis sought to identify patterns and recurring themes, in order to define semantic groupings. After a consensus meeting, the frequencies with which these categories were mentioned by the clinicians were then used to build a graph on diagrams.net, as follows: For the shortcomings (circles), the starting diameter ( 1 mention) was $80 \mathrm{pt}$, which was incremented by $15 \mathrm{pt}$ for each additional mention. The solutions (clouds) started at a width of $120 \mathrm{pt}$, with an incrementation step of $22.5 \mathrm{pt}$.

\section{Results}

Before addressing the second aim of this study - the description of shortcomings and clinicians' needs in the assessment of SDs - we will briefly report on the findings regarding the participants (demographics, initial and continuous training, and characteristics of the SD patient population) and describe the speech disorder assessment practices.

Two hundred and seventy-seven replies were submitted. After a database clean-up (removal of duplicates, of entries in the event of dropping out before the first questions regarding the professional activity, and of those with a negative answer to one of the two filter questions), 119 entries were retained.

The median time for completion of the questionnaire was $20 \mathrm{~min} .47 \mathrm{~s}$. (interquartile range [IQR]: $14 \mathrm{~min} .23 \mathrm{~s}$.).

\section{Description of the population}

\section{SLP participants}

Detailed data for the 119 clinicians whose responses were included in this study are available in Table 1.

The participants, all SLPs, had a median age of 39 years (IQR: 20). Eighty-five percent practiced in France, with a fairly balanced distribution. Most of them practiced as private practitioners $(74 \%)$, with a median of 13.5 years in practice (IQR: 18). Seventy-two percent reported that they had not attended any continuous training in SDs.

SLPs generally considered their level of expertise in SD assessment as "intermediate" (60\%).

This self-assessed level of expertise is related to the proportion of SDs in the overall caseload (Fisher's exact tests: $p=.003)$. It is, furthermore, influenced to a greater extent by the number of years of experience than by the number of SD-related training courses: The probability of considering themselves experts in speech assessment is no greater according to the total number of SD-related training courses, taking into account the years of experience in SD treatment; this is also true for the probability of considering oneself a novice. On the other hand, the probability of considering themselves novice is significantly lower for SLPs with more than 10 years of experience with SDs, compared to those with less than 5 years of experience (logistic regression: $\mathrm{OR}=0.06$ i.e. $94 \%$ less likely; $95 \% \mathrm{CI}=[0.01 ; 0.32]$ ), when adjusting for the total number of SD-related continuous training courses.

\section{Patients with SDs}

Detailed data for patients with SDs are shown in Table 2.

The proportion of patients with SDs in the overall patient population does not exceed one quarter in $62 \%$ of cases. The majority of the affected patients are over 50 years of age (87\%), and most often present with neurological disorders (99\%: neurodegenerative, acquired neurological pathologies, and neurological tumors). SDs have a variable motor and functional impact, and in the vast majority of cases (95\%) induce psycho-emotional consequences and restriction of participation in social activities (92\%).

\section{Clinical assessment of SD: current situation}

\section{Frequency of assessment sessions}

The average number of assessments per quarter (i.e. three months) is 6.32 per SLP. Nearly half of the clinicians perform fewer than three SD assessments per quarter.

\section{Assessment tools}

Test batteries. About a quarter of practitioners (26\%) do not use any existing assessment batteries. Those who do use following batteries, either entirely (34\%) or partially (40\%): Batterie d'Évaluation Clinique de la Dysarthrie (BECD) [34], Évaluation Clinique de la Dysarthrie (ECD, old version of the BECD) [35], Test quantitatif d'intelligibilité [39], 
Table 1. Description of SLPs who participated in the survey.

\begin{tabular}{|c|c|}
\hline \multicolumn{2}{|l|}{ Age } \\
\hline Median & 39 \\
\hline IQR & 20 \\
\hline Min-max & $24-72$ \\
\hline Practice location & $\mathrm{N}(\%)$ \\
\hline \multicolumn{2}{|l|}{ Country } \\
\hline France & $101(85 \%)$ \\
\hline Belgium & $12(10 \%)$ \\
\hline Switzerland & $4(3 \%)$ \\
\hline Algeria & $1(1 \%)$ \\
\hline Tunisia & $1(1 \%)$ \\
\hline \multicolumn{2}{|l|}{ Environment $^{\mathrm{a}}$} \\
\hline Urban & $64(54 \%)$ \\
\hline Suburban & $29(24 \%)$ \\
\hline Rural & $32(27 \%)$ \\
\hline Practice type & $\mathrm{N}(\%)$ \\
\hline Private practice only & $76(65 \%)$ \\
\hline Employed only & $30(26 \%)$, of which $21(70 \%)$ public \\
\hline Mixed & $11(9 \%)$ \\
\hline \multicolumn{2}{|l|}{ Initial training } \\
\hline \multicolumn{2}{|l|}{ Graduation } \\
\hline Median (year of graduation) & 2004 \\
\hline IQR (years) & 21 \\
\hline Min-max & 1975-2018 \\
\hline $2011-2017(N, \%)$ & $35(30 \%)$ \\
\hline \multicolumn{2}{|l|}{ Years of practice } \\
\hline Median & 13.5 \\
\hline IQR & 18 \\
\hline Min-max & $1-44$ \\
\hline$>20$ years $(N, \%)$ & $38(32 \%)$ \\
\hline \multicolumn{2}{|l|}{ Years of SD treatment } \\
\hline Median & 10 \\
\hline IQR & 14 \\
\hline Min-max & $1-42$ \\
\hline \multicolumn{2}{|l|}{ Continuous training } \\
\hline Recent non-SD-related training courses (mean number of separate courses, std) ${ }^{b}$ & $5 \pm 3$ \\
\hline Recent SD-related training courses (mean, std) & $2 \pm 1$ \\
\hline No SD-related training courses $(N, \%)$ & 69 (72\%) \\
\hline \multicolumn{2}{|l|}{ Among the SD-related training courses $(N, \%)$} \\
\hline Voice/speech analysis software training courses $\leq 3$ years & $5(11 \%)$ \\
\hline Voice/speech analysis software training courses $>3$ years & $9(22 \%)$ \\
\hline Self-assessed level of expertise in SDs & $\mathrm{N}(\%)$ \\
\hline \multicolumn{2}{|l|}{ Assessment } \\
\hline Novice & $25(26 \%)$ \\
\hline Intermediate & $57(60 \%)$ \\
\hline Expert & $13(14 \%)$ \\
\hline \multicolumn{2}{|l|}{ Treatment } \\
\hline Novice & $22(23 \%)$ \\
\hline Intermediate & $63(66 \%)$ \\
\hline Expert & $10(11 \%)$ \\
\hline
\end{tabular}

${ }^{\mathrm{a} A}$ combination was possible in the event of multiple working places.

${ }^{\mathrm{b}}$ Within the three years prior to the completion of the questionnaire.

Frenchay Dysarthria Assessment-Second Edition (FDA-2) [54], or MonPaGe protocol [41].

Speech recording. Only two speech therapists report that they do not make any recordings. Three of the 76 clinicians who replied to the question (4\%) carry out recordings in a soundproof room (two employed and one private).

Thirty-five SLPs (29\%) answered the question about the type of microphone used (Figure 1).

Only seventeen participants (14\%) answered the question about the recording mode (mono: 53\%/stereo: 29\%, "I don't know": $18 \%$ ), and eight (7\%) answered the question about the sampling frequency of the recordings.

Thirty-two SLPs (27\%) provided answers to the question of the recording/analysis software being used: Praat $(n=17)$ [55], Vocalab $(n=16)$ [56], Audacity $(n=5)$ [57],
Diadolab [58], and Sound Studio $(n=1)$ [59]. The two SLPs using no software are the same SLPs who do not use a microphone.

Tasks and measures. The most frequently used tasks are word repetition (95\%), spontaneous speech (95\%), orofacial motricity and sensitivity tasks (85\%), text reading (77\%), and sentence repetition (76\%). The other less frequently used tasks (less than 69\%) are, in decreasing order: semidirected speech, word reading, pseudo-word repetition, sentence reading, pseudo-word reading, phonation tasks (maximum phonation time, voice projection, pneumo-phonic coordination), diadochokinesis, and prosody.

The main scores obtained from these tasks (Figure 2) are the global perceptual ratings of "intelligibility" (63\%), "severity" (59\%), and "comprehensibility" (45\%), followed 
Table 2. Description of the SD patient group.

\begin{tabular}{|c|c|}
\hline & $N(\%)$ \\
\hline \multicolumn{2}{|l|}{ SD-patients caseload percentage } \\
\hline $0-25 \%$ & $55(62 \%)$ \\
\hline $25 \%-50 \%$ & $21(24 \%)$ \\
\hline $50 \%-75 \%$ & $6(7 \%)$ \\
\hline $75 \%-100 \%$ & $6(7 \%)$ \\
\hline \multicolumn{2}{|l|}{ Age } \\
\hline Median & 66.75 \\
\hline IQR & 12.5 \\
\hline SD patients $>50$ years $(\mathrm{N}, \%)$ & $76(87 \%)$ \\
\hline Pathologies $^{\mathrm{a}}$ ( & $N(\%)$ \\
\hline Neurological disorders & $85(99 \%)$ \\
\hline Orofacial motor function disorders & $37(43 \%)$ \\
\hline Communication and language disorders in the context of motor, sensory or mental disabilities & $17(20 \%)$ \\
\hline Motor deficits & $N(\%)$ \\
\hline Imprecision of articulatory movements & $80(93 \%)$ \\
\hline Difficulties with rapid sequencing of alternating movements-diadochokinesis & $69(80 \%)$ \\
\hline Slowing of movements & $68(79 \%)$ \\
\hline Muscle tone disorders in the articulators & $62(72 \%)$ \\
\hline Amplitude reduction of simple movements & $58(67 \%)$ \\
\hline Difficulties coordinating simple movements & $47(55 \%)$ \\
\hline Fatigability & $43(50 \%)$ \\
\hline Tremor & $32(37 \%)$ \\
\hline Alteration of the articulators' sensitivity & $31(36 \%)$ \\
\hline Synkinesis & $24(28 \%)$ \\
\hline Impacts on speech & $N(\%)$ \\
\hline Articulatory imprecision of phonemes & $85(99 \%)$ \\
\hline Speech rate impairment (slow, staggered ...) & $77(90 \%)$ \\
\hline Difficulties in phonemic sequencing - in coarticulation & 75 (87\%) \\
\hline Rhinolalia aperta & $48(56 \%)$ \\
\hline Phoneme substitutions & $40(47 \%)$ \\
\hline Phoneme deletions & $40(47 \%)$ \\
\hline Phoneme inversions & $12(14 \%)$ \\
\hline Phoneme additions & $12(14 \%)$ \\
\hline Rhinolalia clausa & $7(8 \%)$ \\
\hline Psychosocial impact & $N(\%)$ \\
\hline Psycho-emotional (low self-esteem, frustration ...) & $82(95 \%)$ \\
\hline Participation in social activities & $79(92 \%)$ \\
\hline Task execution & $34(40 \%)$ \\
\hline Financial repercussions & $16(19 \%)$ \\
\hline
\end{tabular}

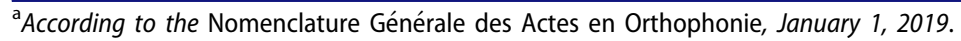

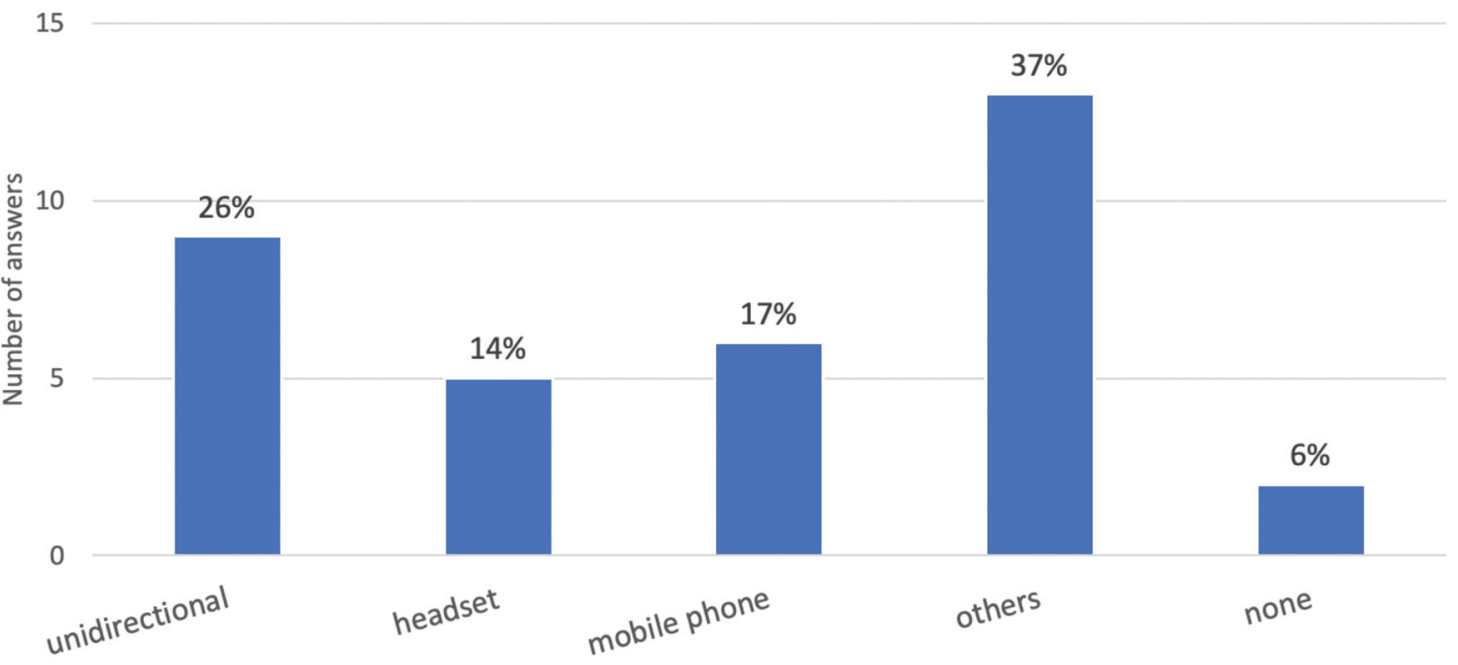

Figure 1. Microphone types used for SD assessment. "Other": standing microphones, dictaphones and lavalier microphones.

by the percentage of errors between expected and perceived phonemes (41\%). Ten SLPs (14\%) report that they do not calculate any scores on the basis of speech tasks.

In the majority of cases (82\%), the clinician solely relies on his or her own judgment. Seventeen percent of the SLPs combine their rating with that of a second listener.
Functional impact and quality of life. The most commonly used speech-related disability/functional impact/quality of life questionnaire is the Voice Handicap Index (70\%) [60]. The Speech Handicap Index (15\%) [42] and the Phonation Handicap Index (11\%) [12] are seldom used. Nearly $25 \%$ of SLPs do not use any questionnaire. 


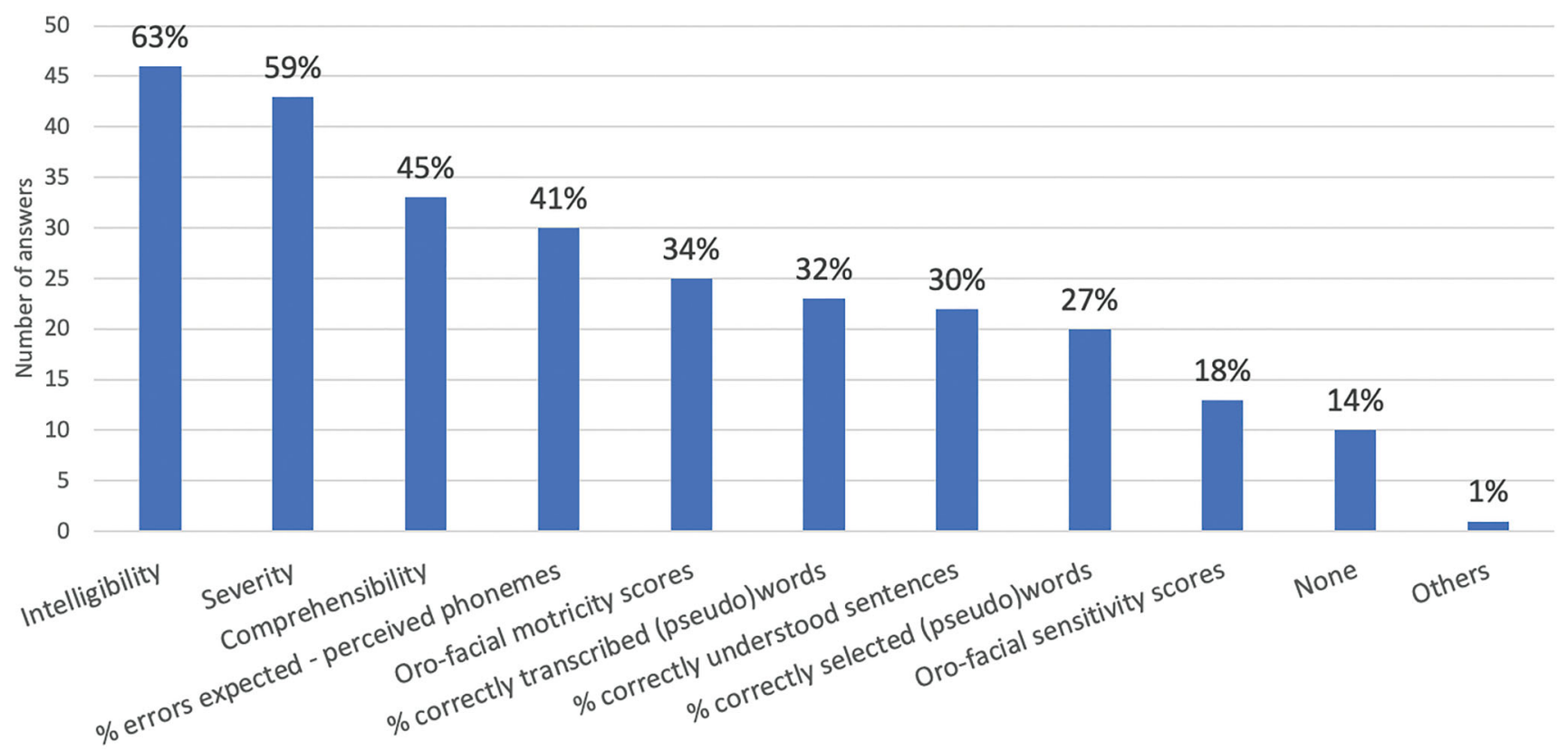

Figure 2. Scores collected in SD assessment.

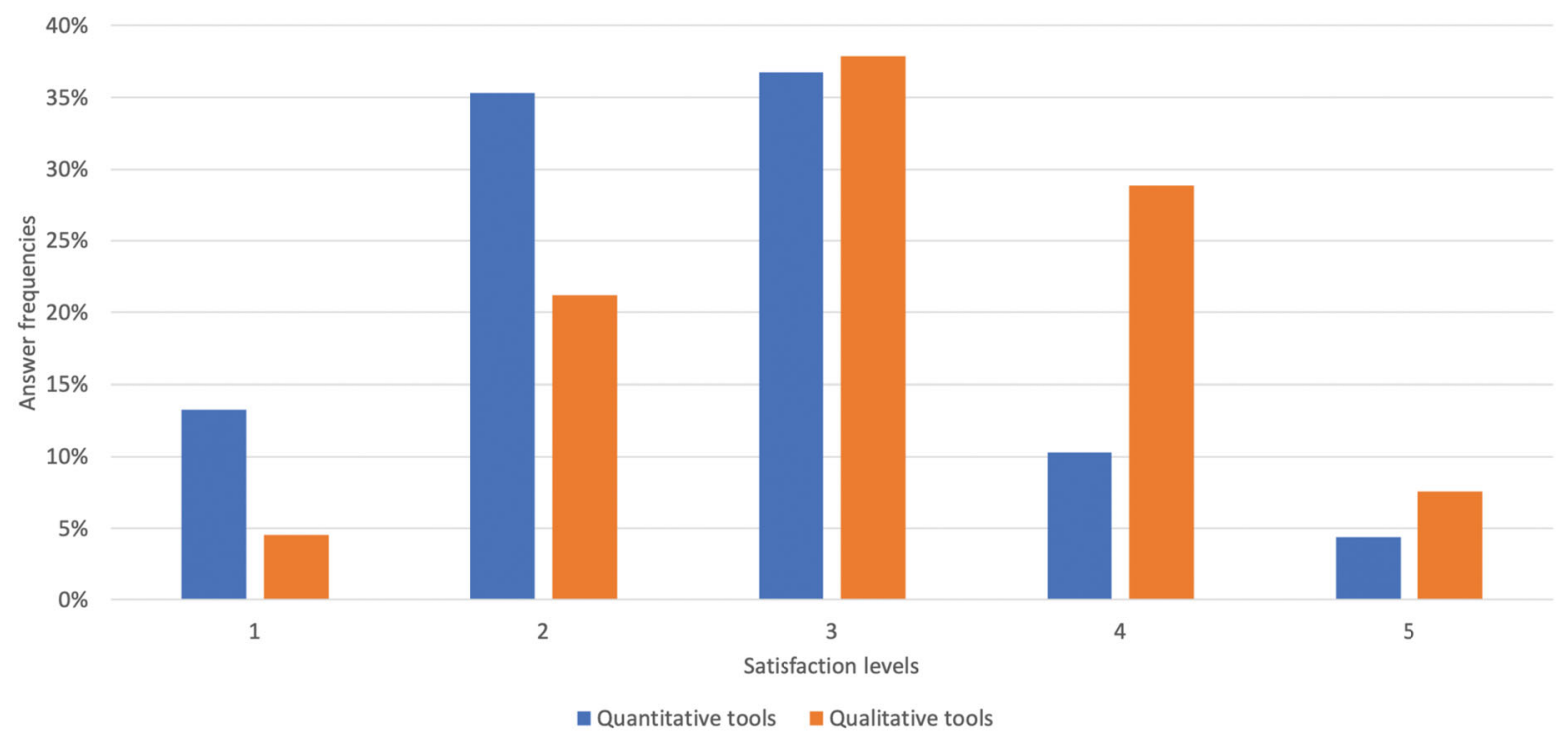

Figure 3. Distribution of satisfaction levels assigned to SD assessment tools.

Assessment duration and patients' fatigability. The median duration of the speech assessment is $78 \mathrm{~min}$, with a case history of $30 \mathrm{~min}(\mathrm{IQR}=20)$ and a test duration of $48 \mathrm{~min}$ $(\mathrm{IQR}=20)$. Most patients with SD have a moderate to high level of fatigability (fatigability level $>3 / 5$ : 93\%).

\section{Shortcomings and needs in SD assessment}

\section{Sufficiency of speech assessment tools}

Overall, the available tools are considered only moderately satisfactory. On a scale ranging from 1 (totally insufficient) to 5 (fully sufficient), quantitative assessment tools are rated significantly lower than qualitative assessment tools $(2.57 \pm 1$ and 3.14 \pm 0.99 , respectively; Mann-Whitney U-test: $p=.001)$. The distribution of allocated satisfaction levels is shown in Figure 3.
The SLPs' comments highlight a lack of reliability in the currently available assessment tools (Appendix A), which are largely based on subjective ratings.

The perception of the sufficiency of the assessment tools is neither influenced by the years of experience in SD treatment (Kruskal-Wallis: $p>.25$ ), nor by the number of SDrelated continuous training courses (Kruskal-Wallis: $p>.46$ ), nor by the number of assessments carried out per quarter (Fisher's exact test: $p>.08$ ).

\section{Reported shortcomings and desired solutions}

The graph in Figure 4 shows the shortcomings reported by the SLPs who took part in this survey, regarding speech assessment tools in adults, as well as desired solutions. 


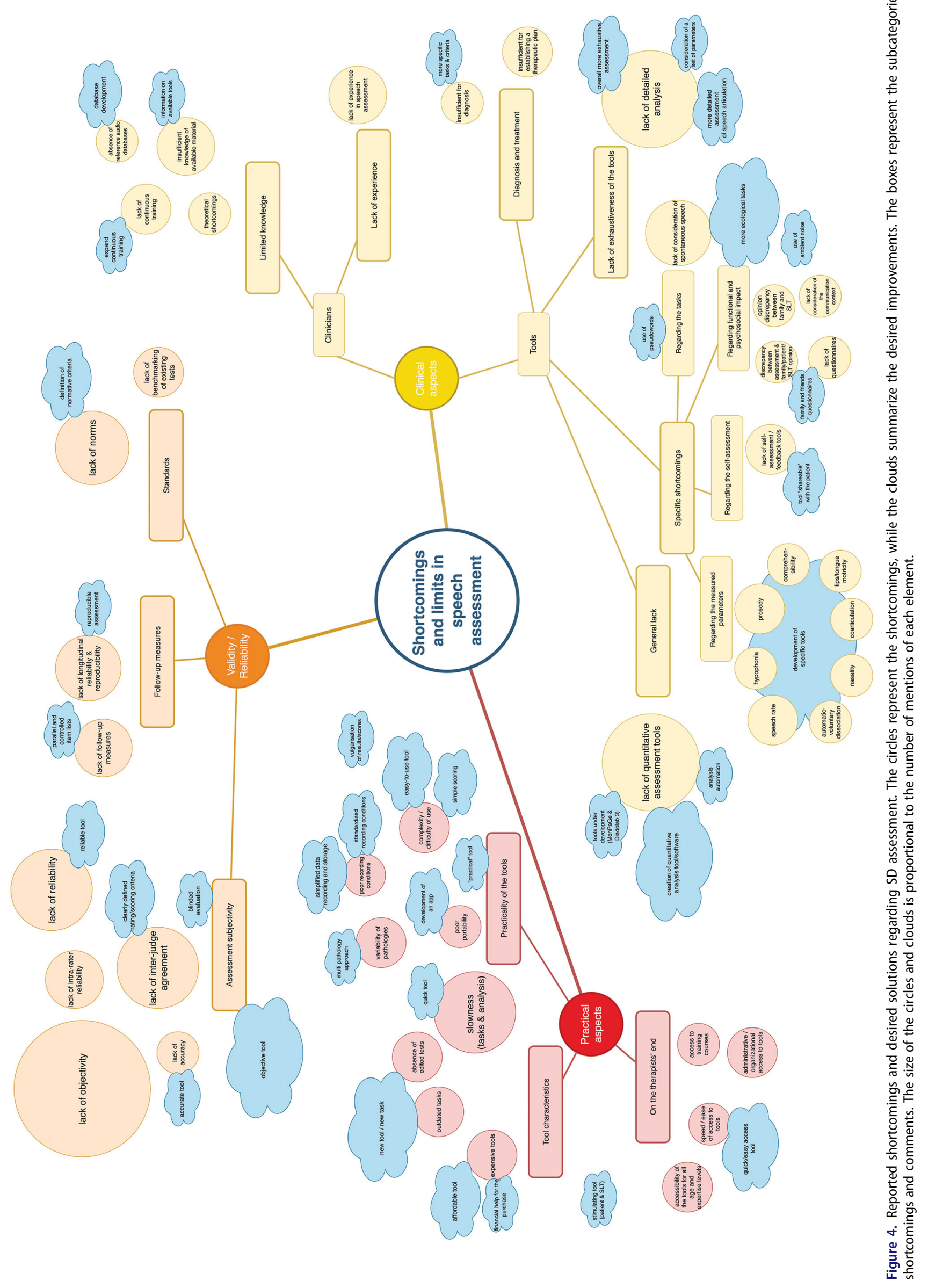


Three main categories of shortcomings emerge from the responses:

- The tools' lack of validity and reliability (upper part in Figure 4): This mainly refers to the subjectivity of these tools, leading to a lack of reliability and reproducibility, as well as a lack of normative benchmarks;

- Difficulties arising from the practical aspects of the use of the tools (left part in Figure 4): Many clinicians complain, inter alia, about the time-consuming and costly nature and the complicated access to and use of the tools;

- Shortcomings in the clinical applicability (right part in Figure 4): The currently available tools lack exhaustivity, are insufficient for diagnosis and treatment planning, and do not allow for the assessment of specific parameters such as prosody, nasality, and speech rate; reliable quantitative assessment tools appear to be lacking to date, and therapists are insufficiently acquainted with them.

Regarding the lack of validity and reliability, according to the reported desired solutions, clinicians would benefit from new reproducible measures, as well as from clearly defined scoring criteria and reference audio databases to improve subjective ratings, and normative data to benchmark the patients' performances.

Still based on the respondents' comments, the practical aspects of using such an assessment tool would be improved by the development of an affordable solution, easy to access as well as to use, with simplified data recording and storing conditions. Portability would also be a great advantage in the clinical contexts.

In order to overcome the lack of exhaustivity of currently existing tools, our results show that a specific focus should also be given to certain parameters such as prosody, nasality, and speech rate. Furthermore, specific tasks, such as the use of pseudo-words to target low-level speech parameters, should be combined with more ecological assessment tasks. In addition, questionnaires addressed to the patient's entourage could allow to getting a more comprehensive picture of the patient's communication.

Finally, clinicians also require better information about existing speech assessment tools and continuous training courses, specifically regarding the acoustic assessment of speech disorders.

\section{Discussion}

As developed in the Introduction, several dimensions need to be addressed in the speech assessment, in order to provide a therapy plan that is tailored to the patient's specific situation (see Appendix B). Our results show that not only does the overall structure of the speech assessment (i.e. the evaluated dimensions) differ across clinicians, but also the assessment tasks used for each dimension, as well as the audio recording procedure. A second important issue that arises from our results and will be discussed is the subjectivity of most of the assessment tasks and the need for more reliable measures.

\section{Standardization}

Overall, a lack of standardization of the speech assessment is highlighted. This can mainly be observed at two levels: the speech production tasks in each dimension of the assessment and the recording conditions.

Regarding the speech production tasks (spontaneous speech, repetition or reading of words, sentences, texts...), most often, SLPs create “à la carte” assessments. Assessment batteries are only used in their entirety by one third of SLPs, while others only draw a few tests from them (thus sometimes overlooking some dimensions of the speech assessment). The preference for this "informal" assessment over standardized tools has been reported internationally in several other surveys $[27,46,48,61]$. Possible causes are the absence of standardized criteria to choose between assessment tools [61], lack of time and funding, dissatisfaction with existing tools, and poor ease of access [27,48]. Note that differences in the health care contexts exist between the French-speaking countries and might explain some of the results. In France for example, where the majority of respondents was practicing, the clinician is given full autonomy in the choice of the assessment tools, whereas in Belgium, more strict guidelines exist that condition the intervention of the national health insurance.

Furthermore, our results show that the limited satisfaction with currently available assessment tools is independent of the clinicians' seniority, of their caseloads and of their continuous training. The overarching nature of this dissatisfaction stresses that the root cause of this feeling very likely comes from the assessment tools themselves and highlights the need to directly address this issue by providing new standardized alternatives.

The recording protocol used by the clinicians also varies widely, which can compromise the reliability of acoustic measures. First, the instructions the clinicians are given remain very flexible, which leads to a great variability in the measurements (e.g. in the BECD, the intensity can be measured on a simple and short sentence or on a sustained vowel). Also, although the recording of the speech signal can affect the measured values, the recording modalities in speech assessments are very disparate. The devices that are used are not standardized, as some clinicians use high-quality microphones, whereas others prefer the use of equipment that is accessible and does not require an additional investment (e.g. their mobile phone). Furthermore, many nonresponses to questions about recording parameters indicate that few SLPs seem to be comfortable with these acoustic parameters, with a likely limited knowledge of them.

To overcome the overall lack of standardization, respondents suggest better information for practitioners about available speech assessment tools, and particularly about the use of acoustic assessment tools, clearer guidelines regarding speech assessment tasks, as well as continuous training courses in speech assessment. 
A better standardization of the speech assessment, at least concerning the dimensions to be evaluated, would have two main benefits. First, it would allow for a repeatable assessment procedure, thus a more reliable gathering of data for follow-up assessments (i.e. intra-rater reliability). Comparisons would not only be made more relevant between the initial and the follow-up assessment for each patient, but also between patients showing similar clinical profiles. Furthermore, in the philosophy of evidence-based practice, homogeneous assessment procedures among professionals would enable easier pooling and comparison of results to promote evidence-based interventions, thanks to a better inter-rater reliability.

Broad recommendations for audio recordings and a general suggestion of a minimal set of tasks for speech assessments in adults, in light of the present results, can be found in Appendix B. These general suggestions are meant to provide an overall structure of the speech assessment but may need adaptations in case of comorbidities (e.g. associated cognitive or sensory deficits) and additional tasks related to specific pathological contexts must be considered. A comprehensive discussion of this minimal set goes beyond the scope of this paper. We will therefore limit our comments to two particular points that were highlighted in our results.

First, it seems that clinicians make little use of pseudowords, probably due to their absence in standard batteries. Some clinicians feel that this is a shortfall. Indeed, the use of pseudo-words allows avoiding "top-down" semantic and syntactic compensation processes [62] and thereby assessing intelligibility, an essential goal in therapeutic care [63]. However, the predominant use of words and sentences indicates that SD assessment does not focus on intelligibility in the analytical sense of the term, but rather on speech comprehensibility. This approach is quite coherent in a clinical context, as it best responds to the patient's complaint, with clinicians focusing more on functional speech tasks. However, the terminology used by SLPs seems to reveal a lack of clarity regarding these concepts: Most say they assess "intelligibility," followed by "disorder severity" and - only in $45 \%$ of cases - "comprehensibility," which, however, appears to be more in line with the notion assessed on the field in view of the employed task. Moreover, ambiguity regarding the definitions of these different terms is not limited to the use by clinicians but is also found in the user manuals of existing batteries ${ }^{3}$, as well as in the scientific literature [64]. Hence, in the first place, the standardization of the speech assessment would benefit from a consensus definition of speech-related terms, such as intelligibility and comprehensibility, to allow for more consistent instructions to the clinician and to avoid any ambiguities. Even more importantly than the terminology, a consensus of the conceptual dimensions that need to be assessed to fulfill the aims of the speech assessment is needed. We believe, for example, that besides a comprehensibility task and an evaluation of the patient's ability to act on his/her communication partners and on the environment, a measure of intelligibility seems equally relevant in speech assessment.
Indeed, the latter allows for more reliable outcome measures as well as for a more specific goal setting when planning therapy. Therefore, our minimal set comprises both "signaldependent" intelligibility tasks as well as more functional comprehensibility assessment tasks.

Second, beyond the symptomatic speech deficit, the patient's complaint also involves the functional and psychosocial repercussions. Strictly biomedical pathological models are not sufficient to describe and understand the impact of communication disorders $[65,66]$, in living and working environments that are specific to each patient. This impact is mostly assessed using questionnaires. However, it appears that the most widely used questionnaire is the Voice Handicap Index, which has been validated for voice disorders and not for speech production disorders. Its use in the context of SDs therefore lacks specificity. The Speech Handicap Index (SHI) and the Phonation Handicap Index (PHI), validated for speech disorders, are seldom used. This observation, combined with the fact that nearly a quarter of speech therapists do not use any questionnaire, highlights the lack of consideration of the impact of deficits on patients' daily lives, despite a growing interest in the quality of life concepts in the medical and paramedical fields [27,67]. It is worth noting that the SHI has been included in the new version of the BECD, on the market since October 2019, demonstrating the growing interest in assessing the functional impact of speech deficits. The PHI, which specifically assesses the speech impairment perceived by the patient, was validated for French in 2009 in a population mainly suffering from neurological disorders [12]; a complementary validation study has then been carried out in 2019, in a population treated for oral or oropharyngeal cancer [11]. Likewise, the validation of the French version of the Dysarthria Impact Profile [68] shows a strong correlation between psychosocial impact scores and "intelligibility" (sic) scores (percentage of correctly transcribed words and sentences).

Last but not the least, we believe that a standardized reading passage specifically created for the assessment of speech and voice is needed. Indeed, a plethora of reading passages exists in various languages, some of which have been created for a specific aim (e.g. the Zoo Passage in English [69], which includes only oral consonants and allows for the assessment of the velopharyngeal closure, or the reading passages by Kuo and Weismer [70], specifically created for the assessment of vowel reduction). However, none of these texts seem to really meet the clinicians and researchers needs for common speech and voice assessments. A unified text, meeting most required criteria for standard speech and voice assessment tasks (e.g. complete phoneme inventory, phonetic balance, presence of clusters, use of various prosodic contours, presence of entirely oral, nasal and voiced sentences, emotionally neutral content/topic...) would therefore be an interesting option. To this end, a multidisciplinary working group as well as an international Delphi consensus survey have been set up. 
Standardization of the speech assessment-what can we do?

- Clear task instructions and guidelines for the clinician

- Standardized minimal task set (see Appendix B)

- Consensus definitions of speech-related terms

- Consensus on the aims and dimensions of the speech assessment

- Recommendations for audio recordings (see Appendix B)

- Better information about available speech assessment tools

- Specific continuous training courses in (acoustic) speech assessment

- Standardized reading passage specifically built for the assessment of speech and voice

\section{Reliability and reproducibility}

Besides the lack of standardization of the speech assessment, another characteristic of speech tests performed in current clinical practice that emerges is their subjectivity, with a high prevalence of perceptual assessment even in "formal" test batteries. The BECD, for example, is based exclusively on perceptual assessment (with the exception of sound pressure level and pitch), which entails an important and widely discussed bias related to the listener's subjectivity, especially since the definitions and rating criteria are prone to a high degree of interpretative variability. The notions of reliability and reproducibility of the assessment are thus crucial points reported by the SLPs who participated in this survey. They also report greater satisfaction with qualitative assessment as compared to quantitative tools, regardless of the number of years of experience with SDs, the number of attended continuous training courses, and the number of assessments performed per quarter. The major use of subjective and qualitative methods highlighted in our data corroborates the results of previous studies, demonstrating a limited use of non-perceptual assessment tools, despite the desire for more reliable means of speech assessment by clinicians given the present subjectivity of both informal and formal assessment $[46,47,61]$.

In order to reduce the subjectivity of the perceptual assessment, several clinicians have expressed the wish for a reference database with pathological speech recordings of varying degrees, in order to better calibrate their judgment of the disorder severity levels. Indeed, numerous studies have shown the improvement of inter-rater reliability through the use of auditory and textual anchors in the assessment of voice and speech samples, in particular through a better perceptual distinction between "healthy" recordings and mild severity levels $[71,72]$.

The use of non-perceptual instrumental measures is another relevant solution to compensate for the lack of objectivity. To date, few such tools are available, and the acoustic parameters used in dysarthria assessment are quite poor. Moreover, they do not focus much on the articulation of speech sounds. A study describing the instrumental assessment of dysarthria in France [53] indicates that it consists mainly of acoustic measures of phonation (intensity, fundamental frequency, jitter, shimmer, vocal range) as well as of aerodynamic measures (e.g. tidal volume, maximum phonation time, duration of sustained $/ \mathrm{s} /$ and $/ \mathrm{z} /$, intraoral pressure). The lack of comprehensiveness of the assessment and of taking into account specific speech parameters (such as prosody, speech rate, and nasality) were indeed shortcomings pointed out by our participants. For future assessment tools, it would therefore be interesting to introduce acoustic measures that are more specific to the speech/ phoneme articulation domain, thus allowing the clinician to obtain an analysis directly related to the speech production performance of their patients. It is worth noting that acoustic speech assessment tools are increasingly being developed. The Diadolab software version 3, for example, was released in April 2019, shortly before the end of the online survey completion period. This software includes an assessment and a treatment module, and uses various acoustic speech measures (prosody, phonology, and diadochokinesis). Only one participant reported using this software. The Carcinologic Speech Severity Index (C2SI) [73] is an automated index for the assessment of speech disorder severity validated on an oncological population, whose score is computed on three tasks (pseudo-word repetition, text reading, and sustained vowel). Finally, the computerized MonPaGe protocol, albeit not yet commercialized, seems to be a promising step toward resolving the two main issues discussed in this study. It uses a standardized set of both perceptual and acoustic measures and combines the investigation of analytical modules such as pseudo-words to assess articulatory precision, with more ecological tasks such as communicative interaction situations [41,74]. However, acoustic methods are still limited to phonation and vowel measures. Consonants also significantly contribute to speech intelligibility [75-77] and should therefore be further investigated for future assessment tools.

Overall, our results show that currently available tools in French-speaking countries do not seem to meet the clinicians' expectations and needs. Similar to surveys in other linguistic communities [27,45-48], our study thus emphasizes the need for new sensitive, standardized, reliable and comprehensive tools to assess speech disorders both at the analytical and at more functional levels. Interestingly, the identified perspectives are similar to those reported by Gurevich and Scamihorn in the USA: "There is support for the need to develop new, cost-effective, useful, efficient, and simple-to-use formal tools to objectively (sic) assess intelligibility (sic). One method of removing subjectivity from assessment of intelligibility (sic) is to turn to technology" [48].

\section{Limits}

The characteristics of our sample suggest a good representativeness of France's SLPs: the mean age (40.4 vs. 43.4 in France), the number of private or mixed practice SLPs $(74 \%$ in the sample vs. $81 \%$ in France), and the number of employed clinicians (26\% in the sample vs. $19 \%$ in France). However, the sample of SLPs who participated in this survey is limited with regard to the overall population of practicing SLPs; results should therefore be interpreted accordingly. 
Also, the fact that responses were not anonymized could have had an effect on the participants' responses. Indeed, clinicians were asked to fill in their names and e-mail addresses, so as to allow the principal investigator to contact them again if and only if they explicitly agreed. While it was specified that the participant's identity was only known to the principal investigator, would not be divulged, and would be removed as soon as it was not needed anymore, this could have induced a response bias. By anonymizing the questionnaire, not only would the response bias have been reduced, but also the number of participants would possibly have been higher, as the non-anonymization seems to have discouraged several respondents who interrupted the questionnaire at the very first page. One "midway" option would have been to only ask for the e-mail address.

It is worth noting that French standardized speech assessment batteries were not available when the survey was carried out: The BECD/ECD was no longer commercially available $^{4}$, and the French translation of the FDA-2 [78] was presented as part of an SLP master's thesis but is still not currently available on the market. While this underlines an inherent lack of standardized speech assessment tools, it has to be taken into account when considering the fact that most SLPs prefer informal ways of SD assessment. Both the availability of speech assessment tools and their limitations contribute to the clinicians' dissatisfaction; their respective contributions, however, remain unknown.

Another limit of this study can be underlined with regard to the patient-related data (see Table 2), which was reported by the participating clinicians. In future studies, in accordance with evidence-based practice (EBP) and patient-centered care (PCC) principles [79], patients' self-reported data should be taken into account instead, especially regarding the psychosocial impact of SDs.

Lastly, no definition of the terms "quantitative" and "qualitative" tools was provided to the participants. The distinction between qualitative, quantitative, subjective, objective, perceptual, and instrumental tools clearly remains open to debate. While the absence of clear-cut definitions should be kept in mind when interpreting the result regarding the lesser satisfaction with "quantitative" tools, other unambiguous elements from the survey results contribute to the conclusion of a major use of subjective perceptual measures, as well as a lack of and need for reliable instrumental methods.

\section{Conclusion}

The results of this study highlight the need to provide new tools for SD assessment, particularly in French, that are reliable/reproducible, easy to use, and financially accessible. This would make the assessment simple, accurate, rapid, ecological, and relevant in the context of the multiple pathologies that can affect speech, with clearly defined interpretation criteria and normative benchmarks. The creation of a new standardized speech assessment tool meeting these criteria, particularly including acoustic measures, would allow for an optimal adaptation to the needs expressed by therapists.
For such a new measure to be reliable and valid, and in view of the limited familiarity of many clinicians with the detailed recording parameters, a more comprehensive training of clinicians in the acoustic assessment of speech, as well as a standardization and simplification of the recording procedure and data storing conditions seem necessary. In addition to this, the assessment would also benefit from the standardization of the dimensions to be assessed and of the task sets (including both pseudo-words and more "ecological" tests, as well as more specific tests for speech rate, nasality, prosody...), as well as of the provided instructions. Based on these observations, a minimal task set together with suggestions for the recording conditions is provided as a guideline for clinicians in Appendix B.

\section{Notes}

1. See the ASHA Practice Portal for a classification of speech sound disorders: https://www.asha.org/practice-portal/ clinical-topics/articulation-and-phonology/

2. https://enquetes.univ-tlse3.fr/index.php/622914?lang=fr

3. In the BECD, for example, intelligibility is described as "the degree of precision with which the message is understood by the listener" (quoting Yorkston and Beukelman, 1980) The "intelligibility score" task is based on word and sentence reading, as well as on "spontaneous" speech (sic), and thus appears to target comprehensibility more closely (in addition, the sub-tests are labelled "word comprehension" and "sentence comprehension").

4. Note, however, that the BECD was available until at least 2012 and has been remarketed in October 2019.

5. It should be noted that the notions of "quantification" and "objectivity" are sometimes confused. A quantitative assessment is not necessarily objective.

\section{Acknowledgments}

The authors thank all the volunteers who gave their time to participate in this survey.

\section{Ethical approval}

All procedures performed involving human participants were in accordance with the ethical standards of the institutional and national research committee and with the 1964 Helsinki declaration and its later amendments or comparable ethical standards.

\section{Disclosure statement}

All authors declare that there is no conflict of interest.

\section{Funding}

This study was supported by Agence Nationale de la Recherche;H2020 Marie Skłodowska-Curie Actions; Hospitals of Toulouse.

\section{Notes on contributors}

Timothy Pommée received a master's degree in Speech and Language Pathology, specialized in Voice Therapy, at the University of Liège (Belgium). He is since 2018 a $\mathrm{PhD}$ student in computer sciences and 
telecommunications at the Institut de Recherche en Informatique de Toulouse (Université Toulouse III Paul Sabatier) in Toulouse (France). His research interests focus on the clinical relevance of speech intelligibility measures.

Mathieu Balaguer graduated as a speech-language pathologist in 2007 at the Université Toulouse III Paul Sabatier in Toulouse (France). He has then worked as a private practitioner for two years, after what he worked as an employed SLP in hospital settings until 2019. He then received a master's degree in Clinical Epidemiology in 2018. He is since 2018 a $\mathrm{PhD}$ student in computer sciences and telecommunications at the Institut de Recherche en Informatique de Toulouse (Université Toulouse III Paul Sabatier) in Toulouse (France). His research interests focus on the automatic assessment of the functional impact of speech disorders on daily communication acts in patients treated for cancer of the oral cavity or oropharynx. He is also involved in education and training of SLP students as lecturer and internships coordinator in the Faculty of Medicine Toulouse-Rangueil since 2010.

Julie Mauclair received a $\mathrm{PhD}$ at the Laboratoire d'Informatique de l'Université du Mans in 2006, entitled "Confidence measures in speech processing and applications". From 2007 to 2009, she was a postdoc in Ireland (UCD) working within the CNGL project addressing the adaptation of digital content to culture, locale and linguistic environment at high volume, speed and quality. Since 2009 she is an assistant professor, first at the University Paris Descartes within the LIPADE laboratory, then in the SAMoVA team at the Institut de Recherche en Informatique de Toulouse. Her research interests focus on characterizing the speech and voice of people presenting with various disorders, using automatic technologies.

Julien Pinquier received a $\mathrm{PhD}$ (computer science specialty) in 2004, related to audio indexing and structuring by search of primary components: speech, music and keysounds. He received the HDR diploma of the University of Toulouse in 2014: this work was based on audio segmentation (speech, music and environmental sounds) and audiovisual segmentation. Since 2005, he is an assistant professor at the Universite Toulouse III Paul Sabatier where he works in the Institut de Recherche en Informatique de Toulouse. His objectives relate to the combination of the audio and the video, the multimedia indexing for automatic structuring of audiovisual documents. He is the author of more than 120 scientific publications. He is the team leader of the SAMoVA team of IRIT. He is now focusing on speech intelligibility measurements.

Virginie Woisard is a phoniatrician and Associate Professor in ENT and Phoniatrics. She is working in the Voice and Swallowing Unit in the ENT department of the Rangueil-Larrey University Hospital in Toulouse, a unit she founded in 1992. She created the Oncorehabilitation Unit at the Cancer Institute of Toulouse in 2014 and is also the head of the Rehabilitaion center for laryngectomized patients at the University Hospital of Toulouse.Author and co-author of numerous publications regarding the assessment and rehabilitation of oropharyngeal dysphagia and speech disorders, she actively participates in the promotion of research on this topic. Involved in several scientific societies (ENT, Phoniatrics, laryngology and dysphagia), she is also a devoted teacher and leader of the University Logopedic Training Center of Toulouse. Her research, as a member of OctogoneLordat, Jean Jaurès University Toulouse II, mainly focuses on the fields of speech disorders. She is the General secretary of the French Phoniatricians Society since 2015.

\section{ORCID}

Timothy Pommée (iD http://orcid.org/0000-0001-7846-7282

\section{References}

[1] Fontan L. De la mesure de l'intelligibilité à l'évaluation de la compréhension de la parole pathologique en situation de communication [From measuring intelligibility to assessing the comprehension of pathological speech in communication situations] [dissertation]. Toulouse: Université Toulouse. 2 Le Mirail; 2012. French.

[2] Woisard V, Espesser R, Ghio A, et al. De l'intelligibilité à la compréhensibilité de la parole, quelles mesures en pratique clinique? [From intelligibility to comprehensibility of speech, what measures in clinical practice?]. Rev Laryngol Otol Rhinol. 2013;134(1):27-33. French.

[3] Ball LJ, Beukelman DR, Pattee GL. Communication effectiveness of individuals with amyotrophic lateral sclerosis. J Commun Disord. 2004;37(3):197-215.

[4] Donovan NJ, Kendall DL, Young ME, et al. The communicative effectiveness survey: preliminary evidence of construct validity. Am J Speech Lang Pathol. 2008;17(4):335-347.

[5] Hartelius L, Elmberg M, Holm R, et al. Living with dysarthria: evaluation of a self-report questionnaire. Folia Phoniatr Logop. 2008;60(1):11-19.

[6] Piacentini V, Zuin A, Cattaneo D, et al. Reliability and validity of an instrument to measure quality of life in the dysarthric speaker. Folia Phoniatr Logop. 2011;63(6):289-295.

[7] Piacentini V, Mauri I, Cattaneo D, et al. Relationship between quality of life and dysarthria in patients with multiple sclerosis. Arch Phys Med Rehabil. 2014;95(11):2047-2054.

[8] Rinkel RN, Leeuw IMV, van Reij EJ, et al. Speech Handicap Index in patients with oral and pharyngeal cancer: better understanding of patients' complaints. Head Neck. 2008;30(7): 868-874.

[9] Walshe M, Peach RK, Miller N. Dysarthria impact profile: development of a scale to measure psychosocial effects. Int J Lang Commun Disord. 2009;44(5):693-715.

[10] Walshe $M$, Miller N. Living with acquired dysarthria: the speaker's perspective. Disabil Rehabil. 2011;33(3):195-203.

[11] Balaguer M, Farinas J, Fichaux-Bourin P, et al. Validation of the French versions of the Speech Handicap Index and the Phonation Handicap Index in patients treated for cancer of the oral cavity or oropharynx. Folia Phoniatr Logop. 2020;72(6): 464-477.

[12] Fichaux-Bourin P, Woisard V, Grand S, et al. Validation of a self assessment for speech disorders (Phonation Handicap Index). Rev Laryngol Otol Rhinol. 2009;130(1):45-51.

[13] World Health Organization. International Classification of Functioning, Disability and Health (ICF). Geneva: World Health Organization; 2001.

[14] Ballard KJ, McCabe P. Developmental motor speech disorders. In: Cummings L, editor. The Cambridge Handbook of Communication Disorders. Cambridge (UK): Cambridge University Press; 2015. p. 383-399.

[15] Dykstra AD, Hakel ME, Adams SG. Application of the ICF in reduced speech intelligibility in dysarthria. Semin Speech Lang. 2007;28(4):301-311.

[16] Ghio A, Lalain M, Giusti L, et al. Une mesure d'intelligibilité par décodage acoustico-phonétique de pseudo-mots dans le cas de parole atypique [A measure of intelligibility by acousticophonetic decoding of pseudowords in the case of atypical speech]. Proceedings of the XXXIIe Journées d'Études sur la Parole. 2018 Jun 4-8; Aix-en-Provence, France. Baixas: ISCA; 2018. p. 285-293. French.

[17] Hustad KC. The relationship between listener comprehension and intelligibility scores for speakers with dysarthria. J Speech Lang Hear Res. 2008;51(3):562-573.

[18] Yorkston KM, Strand EA, Kennedy MRT. Comprehensibility of dysarthric speech. Am J Speech Lang Pathol. 1996;5(1):55-66.

[19] Barefoot SM, Bochner JH, Johnson BA, et al. Rating deaf speakers' comprehensibility: an exploratory investigation. Am J Speech Lang Pathol. 1993;2(3):31-35.

[20] Ghio A, Giusti L, Blanc E, et al. Quels tests d'intelligibilité pour évaluer les troubles de production de la parole? [Which intelligibility tests to assess speech production disorders?]. Proceedings of the JEP-TALN-RECITAL. 2016 Jul 4-8; Paris, 
France. Grenoble (France):AFCP/ATALA; 2016. p. 589-596. French.

[21] Kent RD. Intelligibility in speech disorders. Kent RD, editor. Philadelphia (PA): John Benjamins Publishing Company; 1992.

[22] Miller N. Measuring up to speech intelligibility. Int J Lang Commun Disord. 2013;48(6):601-612.

[23] Xue W, Ramos VM, Harmsen W, et al. Towards a comprehensive assessment of speech intelligibility for pathological speech Interspeech 2020. ISCA: ISCA; 2020. p. 3146-3150.

[24] Palmer R, Enderby P. Methods of speech therapy treatment for stable dysarthria: a review. Adv Speech Lang Pathol. 2007;9(2): 140-153.

[25] Robertson S. The efficacy of oro-facial and articulation exercises in dysarthria following stroke. Int J Lang Commun Disord. 2001;36(s1):292-297.

[26] Duffy JR. Motor Speech Disorders: substrates, differential diagnosis, and management. 3rd ed. St. Louis (MO): Elsevier Mosby; 2013.

[27] Rumbach AF, Finch E, Stevenson G. What are the usual assessment practices in adult non-progressive dysarthria rehabilitation? A survey of Australian dysarthria practice patterns. J Commun Disord. 2019;79:46-57.

[28] Altaher AM, Chu SY, Kam R Binti M, et al. A report of assessment tools for individuals with dysarthria. TOPHJ. 2019;12(1): 384-386.

[29] Kent RD, Weismer G, Kent JF, et al. Toward phonetic intelligibility testing in dysarthria. J Speech Hear Disord. 1989;54(4): 482-499.

[30] Whitehill TL. Assessing intelligibility in speakers with cleft palate: a critical review of the literature. Cleft Palate Craniofac J. 2002;39(1):50-58.

[31] Schiavetti N. Scaling procedures for the measurement of speech intelligibility. In: Kent RD, editor. Intelligibility in Speech Disorders: Theory, measurement and management. Philadelphia (PA): John Benjamins Publishing Company; 1992. p. 11.

[32] Carmichael J. Introducing objective acoustic metrics for the frenchay dysarthria assessment procedure [dissertation]. Sheffield: University of Sheffield; 2007.

[33] Hustad KC. A closer look at transcription intelligibility for speakers with dysarthria: evaluation of scoring paradigms and linguistic errors made by listeners. Am J Speech Lang Pathol. 2006;15(3):268-277.

[34] Auzou P, Rolland-Monnoury V. BECD 2006 - Batterie d'Évaluation Clinique de la Dysarthrie [Dysarthria Clinical Assessment Battery]. Isbergues: Orthoédition; 2006. French.

[35] Auzou P. Évaluation clinique de la dysarthrie [Clinical Assessment of Dysarthria]. Isbergues: Orthoédition; 1998.

[36] Gentil M. Phonetic intelligibility testing in dysarthria for the use of french language clinicians. Clin Linguist Phon. 1992;6(3): 179-189.

[37] Crochemore E. Vannier F. Analyse phonétique de la parole dysarthrique [Phonetic analysis of dysarthric speech]. In: Auzou P, Özsancak C, Brun V, editors. Les dysarthries. Paris: Masson; 2001. p. 71-82. French.

[38] Peckels JP, Rossi M. Le test de diagnostic par paires minimales [The diagnostic test by minimal pairs]. Rev D'acoustique. 1973; 27:245-262. French.

[39] Dittner J, Lepage B, Woisard V, et al. Élaboration et validation d'un test quantitatif d'intelligibilité pour les troubles pathologiques de la production de la parole [Development and validation of a quantitative intelligibility test for pathological speech production disorders]. Rev Laryngol Otol Rhinol. 2010;131(1):9-14. French.

[40] Ghio A, Giusti L, Blanc E, et al. French adaptation of the "Frenchay Dysarthria Assessment 2" speech intelligibility test. Eur Ann Otorhinolaryngol Head Neck Dis. 2020;137(2):111-116.

[41] Lévêque N, Laganaro M, Fougeron C, et al. MonPaGe: un protocole informatisé d'évaluation de la parole pathologique en langue française [MonPaGe: a computerized protocol for the assessment of pathological speech in the French language. Rev Neurol. 2016;172:A162-A163. French.

[42] Degroote G, Simon J, Borel S, et al. The french version of Speech Handicap Index: validation and comparison with the Voice Handicap Index. Folia Phoniatr Logop. 2012;64(1):20-25.

[43] Balaguer M, Percodani J, Woisard V. The Carcinologic Handicap Index (CHI): a disability self-assessment questionnaire for head and neck cancer patients. Eur Ann Otorhinolaryngol Head Neck Dis. 2017;134(6):399-403.

[44] Balaguer $M$, Champenois $M$, Farinas J, et al. The (head and neck) carcinologic handicap index: validation of a modular type questionnaire and its ability to prioritise patients' needs. Eur Arch Oto-Rhino-Laryngology. 2020.

[45] Collis J, Bloch S. Survey of UK speech and language therapists' assessment and treatment practices for people with progressive dysarthria. Int J Lang Commun Disord. 2012;47(6):725-737.

[46] Conway A, Walshe M. Management of non-progressive dysarthria: practice patterns of speech and language therapists in the Republic of Ireland. Int J Lang Commun Disord. 2015;50(3):374-388.

[47] Miller N, Bloch S. A survey of speech-language therapy provision for people with post-stroke dysarthria in the UK. Int J Lang Commun Disord. 2017;52(6):800-815.

[48] Gurevich N, Scamihorn SL. Speech-language pathologists' use of intelligibility measures in adults with dysarthria. Am J Speech Lang Pathol. 2017;26(3):873-892.

[49] La démographie des professions de santé: Orthophonistes (ADELI) [The demographics of health professions: Speech-language pathologists (ADELI)] [Internet]. Paris: Direction de la Recherche, des Études, de l'Évaluation et des Statistiques. 2019. [cited 2020 May 25] Available from: http://www.data.drees. sante.gouv.fr/ReportFolders/reportFolders.aspx?IF_ActivePath= P,490,497,970,1026. French.

[50] Statistiques annuelles des professionnels de soins de santé en Belgique [Annual statistics of health care professionals in Belgium] [Internet]. Bruxelles: Direction générale Soins de Santé. 2018 [cited 2020 May 25]. Available from: https://organesdeconcertation.sante.belgique.be/sites/default/files/documents/ statan_2018_fr_2.pdf. French.

[51] Etudes \& métiers: Professions de santé [Studies \& professions: Health professions] [Internet]. Luxembourg: Cedies. 2020 [cited 2020 May 25]. Available from: https://cedies.public.lu/fr/ publications/sante-social/sante.html. French.

[52] Personnel de santé en Suisse: Etat des lieux et projections à l'horizon 2030 [Healthcare personnel in Switzerland: Current situation and projections to 2030] [Internet]. Neuchâtel: Observatoire suisse de la santé. 2016. [cited 2020 May 25]. Available from: https://www.obsan.admin.ch/fr/publications/ personnel-de-sante-en-suisse French.

[53] Jan M. L'évaluation instrumentale de la dysarthrie en France [Instrumental assessment of dysarthria in France]. In: Auzou P, Rolland-Monnoury V, Pinto S, editors. Les dysarthries. Marseille (France): Solal; 2007. p. 259-269. French.

[54] Enderby P, Palmer R. FDA-2: Frenchay Dysarthria Assessment. 2nd ed. Austin (TX): Pro-Ed; 2008.

[55] Boersma P. Praat, a system for doing phonetics by computer. Glot Int. 2001;5(9/10):341-345.

[56] Menin-Sicard A, Sicard E. Vocalab [software]. St Genis les Ollières (FR): GERIP; 2001. Available from: https://boutiquesante.gerip.com/fr/home/72-pack-vocalab-3.html

[57] Audacity Team. Audacity [software]. 1999-2020. Available from: https://www.audacityteam.org/download/

[58] Menin-Sicard A, Sicard E. Diadolab [software]. St Genis les Ollières (FR): GERIP; 2006. Available from: https://boutiquesante.gerip.com/en/home/73-diadolab.html

[59] Felt Tip Inc. Sound Studio [software]. 2008-2020. Available from: https://felttip.com/ss/

[60] Jacobson BH, Johnson A, Grywalski C, et al. The Voice Handicap Index (VHI). Am J Speech Lang Pathol. 1997;6(3):66-70.

[61] Palmer R. An evaluation of speech and language therapy for chronic dysarthria: The management of dysarthria by practising 
speech and language therapists [unpublished dissertation]. Sheffield: University of Sheffield; 2005.

[62] Ghio A, Lalain M, Giusti L, et al. Du décodage acousticophonétique pour mesurer l'intelligibilité de locuteurs atteints de troubles de production de la parole [Acoustic-phonetic decoding for measuring intelligibility of speakers with speech production disorders]. Paper presented at: 7e Journées de Phonétique Clinique; 2017. Jun 29-30; Paris, France. French.

[63] Walshe M, Miller N, Leahy M, et al. Intelligibility of dysarthric speech: perceptions of speakers and listeners. Int J Lang Commun Disord. 2008;43(6):633-648.

[64] Pommée T, Speyer R, Woisard V, et al. Relationship between phoneme-level acoustic variables and speech intelligibility in healthy speech: A systematic review. [manuscript submitted for publication]. Speech Lang Hear. 2020.

[65] Wade DT, Halligan PW. Do biomedical models of illness make for good healthcare systems? BMJ. 2004;329(7479):1398-1401.

[66] Wray F, Clarke D. Longer-term needs of stroke survivors with communication difficulties living in the community: a systematic review and thematic synthesis of qualitative studies. BMJ Open. 2017;7(10):e017944-18.

[67] Organisation mondiale de la santé. Classification internationale du fonctionnement, du handicap et de la santé: CIF. Genève; 2001.

[68] Atkinson-Clement C, Letanneux A, Baille G, et al. Psychosocial impact of dysarthria: the patient-reported outcome as part of the clinical management. Neurodegener Dis. 2019;19(1):12-21.

[69] Fletcher SG. Contingencies for bioelectronic modification of nasality. J Speech Hear Disord. 1972;37(3):329-346.

[70] Kuo C, Weismer G. Vowel reduction across tasks for male speakers of American English. J Acoust Soc Am. 2016;140(1): 369-383.

[71] Awan SN, Lawson LL. The effect of anchor modality on the reliability of vocal severity ratings. J Voice. 2009;23(3):341-352.

[72] Brinca L, Batista AP, Tavares AI, et al. The effect of anchors and training on the reliability of voice quality ratings for different types of speech stimuli. J Voice. 2015;29(6):776.e7-e14.

[73] Astésano C, Balaguer M, Farinas J, et al. Carcinologic Speech Severity Index project: a database of speech disorder productions to assess quality of life related to speech after cancer. Proceedings of the Eleventh International Conference on Language Resources and Evaluation (LREC 2018); 2018 May 712; Miyazaki, Japan. Paris: European Language Resources Association (ELRA); 2018.

[74] Pernon M, Lévêque N, Delvaux V, et al. MonPaGe, un outil de screening francophone informatisé d'évaluation perceptive et acoustique des troubles moteurs de la parole (dysarthries, apraxie de la parole [MonPaGe, a computerized French-language screening tool for the perceptive and acoustic evaluation of motor speech disorders (dysarthria, speech apraxia].
Rééducation orthophonique. 2020. 281:169-198. French.

[75] Owren MJ, Cardillo GC. The relative roles of vowels and consonants in discriminating talker identity versus word meaning. J Acoust Soc Am. 2006;119(3):1727-1739.

[76] Bonatti LL, Peña M, Nespor M, et al. Linguistic constraints on statistical computations: The role of consonants and vowels in continuous speech processing. Psychol Sci. 2005;16(6):451-459.

[77] Chang S-A, Park M-H, Oh S-H, et al. Influence of upper frequency boundary on consonant perception in normal hearing and cochlear implant adults. Audiol Speech Res. 2017;13(3): 231-239.

[78] Blanc E, Giusti L. Évaluation de l'intelligibilité de la parole dans les dysarthries: adaptation en français de la version révisée du Frenchay Dysarthria Assessment (FDA-2) [Assessment of speech intelligibility in dysarthria: French adaptation of the revised Frenchay Dysarthria Assessment (FDA-2)] [master's thesis]. Marseille: Aix-Marseille Université; 2014. French.

[79] Vranceanu A-M, Cooper C, Ring D. Integrating patient values into evidence-based practice: effective communication for shared decision-making. Hand Clin. 2009;25(1):83-96.

[80] Chial MR. Suggestions for computer-based audio recording of speech samples for perceptual and acoustic analyses. Madison, WI: Waisman Center, University of Wisconsin-Madison; 2003. (Phonology Project; Tech. Rep. No. 13). Available from: https:// citeseerx.ist.psu.edu/viewdoc/download?doi=10.1.1.118.5826\& rep=rep1\&type $=$ pdf.

[81] Deliyski DD, Shaw HS, Evans MK. Adverse effects of environmental noise on acoustic voice quality measurements. J Voice. 2005;19(1):15-28.

[82] Patel RR, Awan SN, Barkmeier-Kraemer J, et al. Recommended protocols for instrumental assessment of voice: American Speech-Language-Hearing Association expert panel to develop a protocol for instrumental assessment of vocal function. Am J Speech Lang Pathol. 2018;27(3):887-905.

[83] Šrámková $\mathrm{H}$, Granqvist S, Herbst CT, et al. The softest sound levels of the human voice in normal subjects. J Acoust Soc Am. 2015;137(1):407-418.

[84] SVec JG, Granqvist S. Guidelines for selecting microphones for human voice production research. Am J Speech Lang Pathol. 2010;19(4):356-368

[85] Švec JG, Granqvist S. Tutorial and guidelines on measurement of sound pressure level in voice and speech. J Speech Lang Hear Res. 2018;61(3):441-461.

[86] Plichta B. Best practices in the acquisition, processing, and analysis of acoustic speech signals. U. Penn Working Papers in Linguistics. 2002;8(3):209-222

[87] Winholtz WS, Titze IR. Miniature head-mounted microphone for voice perturbation analysis. J Speech Lang Hear Res. 1997; 40(4):894-899. 


\section{Appendix A.}

\section{Examples of comments about satisfaction with speech assessment tools}

- "I have the feeling that I'm making a qualitative rather than quantitative assessment, despite the use of the ECD battery";

- "The scoring, even if it is meant to be objective", remains a function of the examiner, his/her sensitivity and what he/she considers to be pathological (experienced SLT vs. trainee or novice SLT for example)";

- "Longitudinal reliability if we keep the same recording methods and the same judge (however, bias in the evaluation), delicate inter-judge reliability";

- "In my opinion, there's a fair amount of subjectivity of the practitioner when scoring the patient's performance on certain items";

- "Absolutely non-reproducible assessment, therefore unreliable!";

- "Lack of objective tools especially on the overall severity of the speech disorder and on the quantification of segmental alterations"

\section{Appendix B.}

Minimal set of tasks and recording requirements for speech disorder assessment in adults

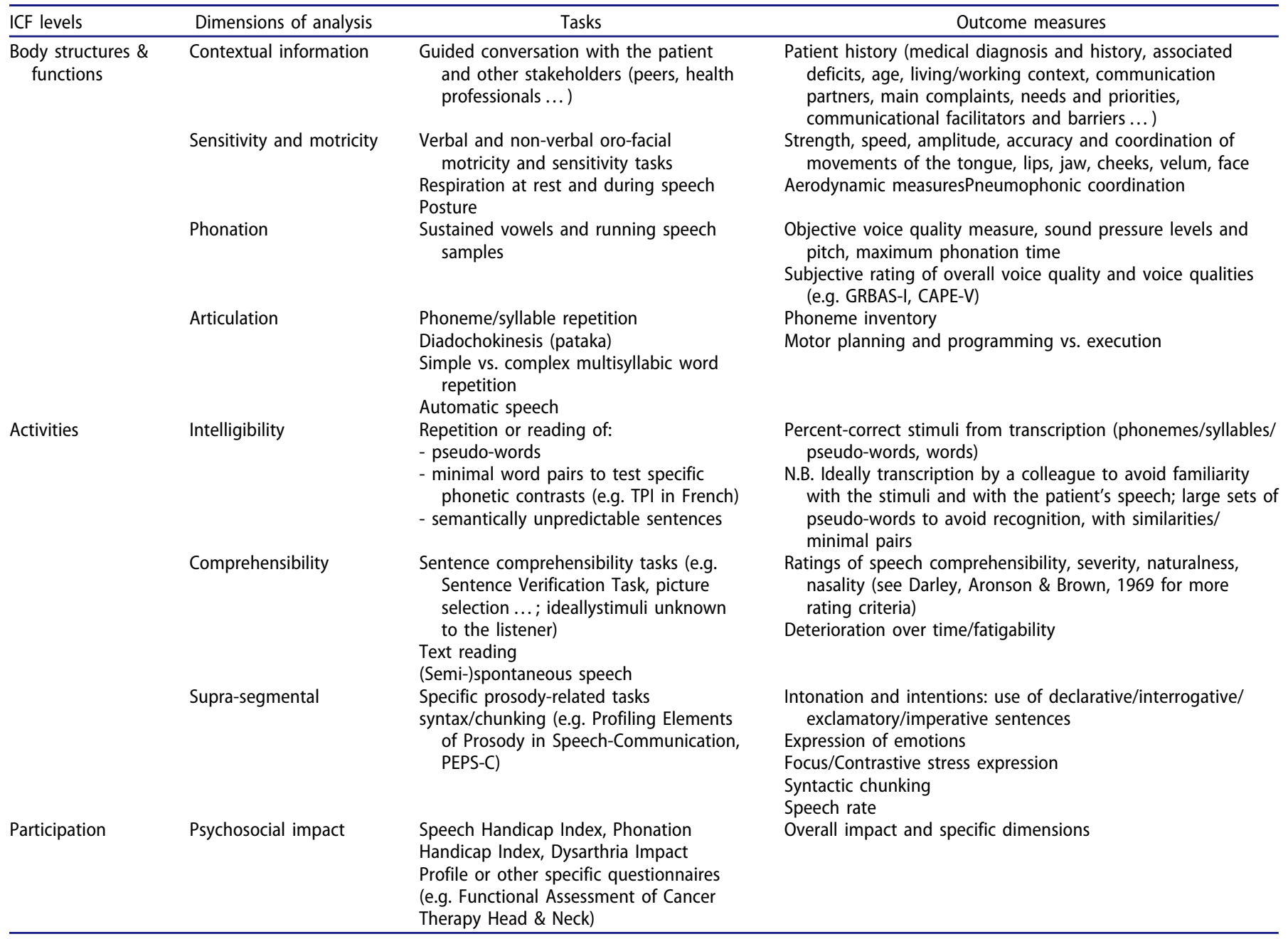


Recording conditions [80-87]

For research purposes, all of the following parameters should be kept constant; for clinical purposes, the parameters should be kept constant for each patient (e.g. the entry level can sometimes need adaptation with regard to the patient's profile, such as for singers or for patients with a very low voice level, but should then be set identically for follow-up recordings).

Microphone:

- head-mounted microphone to allow for a consistent microphone-mouth distance and maximize the signal-to-noise ratio

- cardioid (directional) microphone to limit ambient noise effect and maximize signal-to-noise ratio (for research purposes, omnidirectional microphone for better SPL and frequency accuracy)

- transducer type (conversion of the acoustic pressure into electric signal): condenser

- frequency response: wide and flat range (i.e. $<2 \mathrm{~dB}$ variation), ideally $10 \mathrm{~Hz}-20.000 \mathrm{~Hz}$; at least $50 \mathrm{~Hz}-8000 \mathrm{~Hz}$ to capture the whole speech/voice spectrum

- dynamic range: $15-130 \mathrm{~dB}$; the internal noise level of the microphone (see manufacturer's specifications) should be at least $15 \mathrm{~dB}$ lower than softest phonation, i.e. noise level of max. $30 \mathrm{dBA}$ when the microphone is used at a $5 \mathrm{~cm}$ distance from the mouth

- use foam tips to avoid turbulences on plosives, fricatives or airflow noise

- $4-10 \mathrm{~cm}$ from the patient's mouth at a $45-90^{\circ}$ angle (try to always use the same distance, as this has a large impact on intensity measures); the optimal distance for a flat frequency response (necessary for spectral measures) should be provided in the microphone specifications

Preamplifier:

The preamplifier amplifies the low microphone signal amplitude/voltage:

- use a preamplifier that has the same frequency response and dynamic range as the microphone

- check the "minimum terminating impedance" in the microphone specifications

- the condenser microphone needs to be powered through the "phantom power supply", usually $48 \mathrm{~V}$

- entry level: adjust it so that the maximum voice levels are closest to but below the maximum recordable levels of the device (avoid saturation)

Digital recording:

- minimum sampling rate: $44.1 \mathrm{kHz}$

- minimum amplitude resolution: $16-$ bit

- file format: .wav file (no compression; do NOT use .mp3)

- recording mode: mono

General suggestions:

- Try stick to a single recording/analysis software: Praat (free), Audacity (free), Computerized Speech Lab (commercial)...

- Calibrate the microphone for intensity measures: record a stable pure tone from a speaker or a sustained vowel with the head-mounted microphone and simultaneously use a sound level meter at the exact same distance; compare the intensity measured through the microphone (e.g. using Praat) with the value on the sound level meter, which gives you the reference value. If for example Praat indicates $65 \mathrm{~dB} S P L$, while the sound level meter reports $60 \mathrm{~dB}$ $\mathrm{SPL}$, for all future measures made with the exact same distance and parameters, subtract $5 \mathrm{~dB}$ from the computer measure to get the "real" sound pressure level.

- Carry out the recordings in a quiet room. If no soundproof room is available, measure the ambient noise using a sound level meter; considering that the signal-to-noise ratio should be higher than $42 \mathrm{~dB}$ for reliable acoustic measures (although $>30 \mathrm{~dB}$ is acceptable), and that the average conversational voice intensity is about $60 \mathrm{~dB}$, the ambient noise should be less than $18 \mathrm{~dB}$ to allow for an optimal signal-to-noise ratio.

- Avoid noise sources such as fan/AC, computer hum, buzzing neon lights ... but also smartphones and other connected accessories like smart watches, which can induce interference noise 